\title{
Spontaneous Intracranial Hypotension as a Cause of Exacerbation in Huntington's Disease - ADDENDUM
}

\section{Enriqueta Lúcar Figueroa, Mandar S. Jog, David M. Pelz, Stephen P. Lownie}

Keywords: Spontaneous intracranial hypotension, Huntington's disease, Epidural blood patch, Subdural hematomas; addendum

doi: https://doi.org/10.1017/cjn.2018.52, Published by Cambridge University Press, 25 May 2018

In the issued erratum notice ${ }^{1}$ for "Spontaneous Intracranial Hypotension as a Cause of Exacerbation in Huntington's Disease" by Lúcar Figueroa et al. ${ }^{2}$, the wrong volume and issue numbers were cited for the original article.

The publisher regrets this error, and the notice has been updated.

\section{REFERENCES}

1. Lúcar Figueroa E, Jog MS, Pelz DM, Lownie SP. Spontaneous intracranial hypotension as a cause of exacerbation in
Huntington's disease - ERRATUM. Can J Neurol Sci First published online 25 May 2018. Doi: 10.1017/cjn.2018.52

2. Lúcar Figueroa E, Jog MS, Pelz DM, Lownie SP. Spontaneous intracranial hypotension as a cause of exacerbation in Huntington's disease. Can J Neurol Sci. 2018;45(3):357-9; Doi: 10.1017/ cjn.2017.296 